\title{
ACCEPTED FOR THE IMPACT FACTOR - WHAT IS THE IMPACT OF EUROSURVEILLANCE?
}

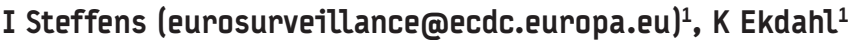 \\ 1. European Centre for Disease Prevention and Control, Stockholm, Sweden
}

This article was published on 24 September 2009.

Citation style for this article: Steffens I, Ekdahl K. Accepted for the impact factor - what is the impact of Eurosurveillance?. Euro Surveill. 2009;14(38):pij=19339. Available online: http://www.eurosurveillance.org/ViewArticle.aspx?ArticleId=19339

Publications in impact factor journals have become an essential determinant of scientific careers and their listing plays a central role in the evaluation of grants, promotions etc. The scientific community judges the quality and importance of a journal and of individual publications by the impact factor which is awarded by a company called Thompson Reuters.

After several recent improvements to the journal, such as the merging of the former monthly and weekly editions into one weekly edition in January 2008 and the launch of a new website in April 2008, we embarked on an evaluation, in collaboration with a medical librarian, of whether our journal met the inclusion criteria for an impact factor [1]. We applied for the impact factor in October 2008 and are pleased to announce that Eurosurveillance has recently been selected for coverage by Thomson Reuters and is now indexed and abstracted in the Science Citation Index Expanded (also known as SciSearch $囚$ ) and in the Journal Citation Reports/ Science Edition, beginning with Volume 14(1) 2009.

The basis for the calculation of the impact factor is the frequency with which the average article in a given journal has been cited in a defined period [2]. For Eurosurveillance, we expect the allocation of our first official impact factor for 2011, after the two-year evaluation period. It will be calculated as a ratio with the total number of citable articles published in Eurosurveillance in 2009 and 2010 as the denominator and the number of citations these articles receive in indexed journals in 2011 as the numerator. Generally, citable items are articles, reviews, proceedings or notes, while editorials or letters to the editor are excluded.

Obvious challenges lie ahead of us, and we will maintain our efforts to select the most interesting articles of high quality for our readers while at the same time supporting capacity building across Europe by lending assistance to less experienced authors. However, in the field of public health and communicable diseases, the real impact of a journal is determined by more than the calculated value of the impact factor. When dealing with outbreaks or emerging diseases, it is important that authoritative information is disseminated rapidly and reaches a wide range of stakeholders. Public health experts and policy makers require scientifically sound information that will allow them to choose necessary and appropriate public health actions.

In the past months, Eurosurveillance has proven to have an impact on public health by documenting the emerging H1N1 influenza pandemic in numerous reports not only from Europe but also from North and South America, Asia, Australia and New Zealand. In 61 articles to date, we have covered relevant aspects of the pandemic from modelling and phylogenetic analysis to antiviral treatment and vaccination. The majority of articles were rapid communications that we were able to process within one week from submission thanks to authors and peer reviewers who agreed to work to tight deadlines despite their already high work load. We are grateful for this support, and the efforts have paid off. Papers published in Eurosurveillance were further disseminated through channels such as ProMEDMail (http://promedmail.oracle.com/pls/ otn/f?p=2400:1000:) and the Lancet H1N1 flu resource centre (http://www.thelancet.com/H1N1-flu). They featured widely in the general media and caught the attention of many experts and high level policy makers. Articles in Eurosurveillance were cited by a co-chairman of President Obama's Council of Advisors on Science and Technology [3].

We are confident that authors, reviewers and readers will continue to support us in our efforts to publish relevant and influential information of high quality, and that in two years time, these efforts will be manifest not only in the assigned impact factor but also in our actual impact for public health in Europe.

\section{References}

1. Escriva AB, Steffens I. The collaboration of the ECDC Library in the pursuit of the Eurosurveillance impact factor. JEAHIL. 2009;5(3):11-17. Available from: http://www.eahil.net/journal/journal_2009_vol5_n3.pdf

2. Thomson Reuters. Introducing the impact factor. Available from: http://www. thomsonreuters.com/products_services/science/academic/impact_factor/

3. Michael Fumento. Flu forecast is based on suspect data. The Philadelphia Enquirer; 2009, September 2. Available from: http://www.philly.com/inquirer/ opinion/20090902_Flu_forecast_is_based_on_suspect_data.html 